\title{
Opening of the Vena Cava
}

National Cancer Institute

\section{Source}

National Cancer Institute. Opening of the Vena Cava. NCI Thesaurus. Code C33214.

The orifices through which the superior and inferior vena cava drain blood into the right atrium. 